\title{
A ANÁLISE ECONÔMICA DO DIREITO E A MODERNA ATIVIDADE EMPRESARIAL
}

Nathalie de Paula Carvalho

Mestranda em Direito Constitucional pela Universidade de Fortaleza e bolsista da Funcap.

nathaliedireito@hotmail.com

Sumário: Introdução. 1) A Análise Econômica do Direito (AED). 2) A moderna atividade empresarial. 3) O comportamento do consumidor. 4) A teoria dos custos de transação. 5) A concorrência e a defesa do consumidor nas modernas relações empresariais. Conclusão.

Resumo: O presente artigo tem como objetivo principal analisar como se manifesta o comportamento das empresas frente ao mercado consumidor nos ditames da Análise Econômica do Direito (AED), também conhecida como Escola de Chicago. Verificar-se-á algumas considerações sobre a AED, passando-se ao estudo da moderna atividade empresarial, sob a ótica da teoria dos custos de transação, do mercado consumidor que a alimenta, concluindo-se pela relação direta e significativa entre o Direito Empresarial e a ordem econômica como balizadores da atuação do empresariado atual.

Palavras-chave: Análise Econômica do Direito. Empresas. Consumidor.

\section{INTRODUÇÃO}

A escola da Análise Econômica do Direito, também conhecida como Escola de Chicago, procura implementar os postulados econômicos na aplicação e interpretação de paradigmas jurídicos, com a meta de aumentar o grau de previsibilidade e eficiência das relações econômicas, sociais e jurídicas.

Os principais pontos desta escola são condensados na rejeição da posição que analisa o Direito apartado das realidades sociais e econômicas, estimulando a utilização das idéias e métodos de outras disciplinas no estudo conjunto com a economia e a política, enaltecendo a interdisciplinariedade.

O presente artigo tem a função de definir e modelar a moderna atividade empresarial frente à Análise Econômica do Direito e a teoria dos custos de transação, direcionando principalmente para a questão da proteção do consumidor e investigar como a concorrência se materializa na atual conjuntura econômica. 


\section{A Análise Econômica do Direito (AED)}

A Análise Econômica do Direito (AED), também conhecida por Escola de Chicago, tem como principal objetivo de aplicar os postulados econômicos na interpretação de conceitos jurídicos, buscando aumentar o grau de previsibilidade e eficiência das relações inerentes ao ordenamento jurídico. Embora no século XVIII Adam Smith já discutisse o efeito econômico da legislação mercantilista, foi apenas recentemente que se aplicou a economia para analisar atividades não diretamente relacionadas ao mercado. Ronald Coase, Richard Posner (1998) e Guido Calabresi são os principais nomes da Análise Econômica do Direito.

Posner (1998, p.26) observa que as origens da AED estão ligadas ao Common Law, cuja prevalência é pelo direito jurisprudencial, ou seja, baseado em precedentes judiciais, sendo apontado por ele como o campo por excelência da maximização da riqueza de uma sociedade. Sobre o assunto, Fernando Herren Aguillar assevera que:

Nos últimos anos, em que há um claro predomínio de políticas liberalizantes, é notável como as escolas de pensamento no Direito Econômico são progressivamente influenciadas por metodologias que prestigiam o econômico mais do que o jurídico. Assim como no século XIX se ensinava Economia Política e se tratava a medida econômica como mera questão de acerto ou erro científico, as correntes contemporâneas do Law and Economics colocam em primeiro plano a economia para a aplicar o Direito. (AGUILLAR, 2006, p.36-37).

O foco da AED é unir a Economia ao Direito para estudar as regras legais e instituições, usando o pressuposto de comportamento racional por parte dos indivíduos como principal instrumento de raciocínio: "empresas e mercados são instituições ou institutos que estão na fronteira entre o direito e a economia." (SZTAJN, 2004, p.27).

Para isso, usa a análise econômica para prever os efeitos das leis, v.g. quais as conseqüências econômicas da responsabilidade subjetiva em comparação com a responsabilidade objetiva, além de dedicar-se a explicar o desenvolvimento das leis em termos de eficiência econômica, o que seria a AED normativa por meios dos conceitos de otimização de Vilfredo Pareto ou Kaldor-Hicks como critérios de eficiência (FORGIONI, 2005). Por este, uma mudança em que alguns indivíduos sejam prejudicados é possível, desde que aqueles que melhorem de posição ganham mais do que perdem aqueles que pioram de situação. Por aquele, uma sociedade não se encontra em uma situação ótima se não houver pelo menos uma modificação capaz de melhorar a posição de alguém, sem prejudicar a de outra.

As principais obras de Coase são "The Problems of Social Cost" (1960) e "The nature of the firm" (1937), por meio das quais foca no desenvolvimento da economia dos Custos de Transação na moderna AED e na Teoria das Organizações. 
Estuda-se, pois, conjuntamente, o Direito, a Economia, as instituições e as organizações, haja vista que o Direito influencia e é influenciado pela Economia, refletindo nas organizações e instituições. Nessa linha de raciocínio, Rachel Sztajn afirma que:

A análise econômica deve, então, considerar o ambiente normativo no qual os agentes atuam, para não correr o risco de chegar a conclusões equivocadas ou imprecisas, por desconsiderar os constrangimentos impostos pelo Direito ao comportamento dos agentes econômicos. O Direito, por sua vez, ao estabelecer regras de conduta que modelam as relações entre pessoas, deverá levar em conta os impactos econômicos que delas derivarão, os efeitos sobre a distribuição ou alocação de recursos e os incentivos que influenciam o comportamento dos agentes econômicos privados. (SZTAJN, 2005, p.03).

O principal papel das instituições seria interferir diretamente na performance econômica. Com a tecnologia empregada, determinam os custos de transação. Em 1960, emerge o Teorema de Coase, na obra "The Problems of Social Cost". Prega que, em um mundo hipotético, ou seja, sem custos de transação, os agentes econômicos negociariam os direitos, independentemente de uma alocação eficiente e não interfeririam no desempenho econômico.

Essa visão (a neoclássica) foi criticada por Coase, uma vez que, para ele, no mundo real os custos de transação são positivos e o impacto das instituições legais são marcantes: para realizar-se uma transação no mercado é fundamental descobrir com quem transacionar, fornecer informações, redigir um contrato e monitorar o seu cumprimento.

\section{A MODERNA ATIVIDADE EMPRESARIAL}

"Empresários são os propulsores da atividade econômica, são os agentes que organizam a produção": é assim que Rachel Sztajn (2004, p.13) define o papel do empresariado à luz da Análise Econômica do Direito, valorizando-se, além da iniciativa privada, a cooperação interempresarial de modo a facilitar a organização das atividades empresariais, o que é interessante para o sistema produtivo. Assim, depreende-se que os mercados e as empresas se complementam, estão na fronteira entre o Direito e a Economia, na medida em que aqueles incentivam a produção de bens em qualidades e quantidades correspondentes à demanda existente.

Destaca-se também a importância dos contratos, da livre iniciativa, livre concorrência (art. 170 da Constituição Federal) e da propriedade privada: "contratos facilitam a circulação de propriedade; empresas organizam a produção para os mercados estes tornam eficiente a troca econômica." (SZTAJN, 2004, p.29). Vai mais além: 


\begin{abstract}
Além de jurídico, o contrato é uma instituição social cuja função serve para dar segurança aos agentes econômicos nas relações patrimoniais que entre si venham a ajustar. Essa função não encontra paralelo em qualquer outro instituto jurídico, nem pode ser absorvida por qualquer deles. Seria possível, sem contratos, promover a regular e segura circulação de bens em uma dada sociedade? Sem contratos, a liberdade para dispor, livremente, dos próprios interesses ficaria prejudicada. (SZTAJN, 2005, p.29).
\end{abstract}

O conceito de empresa, segundo Francesco Galgano (1976, p.193), foi mencionado pela primeira vez no Código Francês de 1808, no século XIX. Em 1942, o Código civil italiano trata a empresa como uma atividade produtiva. A empresa, com o desenvolvimento das relações mercadológicas, passa a ser vista como "organização" e sua atuação é assim elucidada:

A intensidade do tráfico negocial imposto pela industrialização incipiente requer regras que contemplem não apenas a velocidade com que as operações são realizadas, mas, sobretudo, a repetição de padrões e a necessidade de novos instrumentos que reflitam as mudanças no processo negocial. (SZTAJN, 2004, p.22).

A empresa é uma categoria de produção, porque este processo supera o da circulação de mercadorias e a atividade vai sendo paulatinamente organizada. A importância dessa nova visão tem duas razões: a primeira é o aspecto socialmente útil da atividade sobre o especulativo e a segunda é a necessidade de se trabalhar com um conceito funcional para adequar-se a uma economia controlada. $\mathrm{O}$ empresário criava riquezas, mas dentro de um ordenamento jurídico positivado. Para Fábio Ulhôa Coelho:

Certamente, o dirigismo econômico importou a restrição da margem de livre atuação da vontade particular. A anarquia do mercado, se não podia ser de todo eliminada, como pretendido pelo fracassado ideal socialista de planificação estatal da economia, devia ser pelo menos controlada, e isto, no plano jurídico, representou o aumento da regulação dos interesses econômicos pele interferência da ordem positivada, externa à vontade das pessoas diretamente envolvidas. (COELHO, 2006, p.09).

O art. 966 do Código Civil brasileiro define o empresário como aquele que exerce profissionalmente atividade econômica organizada para a produção ou a circulação de bens ou serviços. Adotou-se, pois, a Teoria da Empresa, herança do direito italiano. O legislador não se orientou, portanto, pela Teoria da firma, pela qual a entidade empresarial teria uma meta de reduzir os custos de transação por meio de contratos, visão esta que se coaduna com a escola neo-institucionalista. Essa formulação pertence a Ronald Coase, para quem as empresas são feixes de contratos. 
Faz-se necessário, neste momento, apresentar-se uma explanação sobre a Teoria da Firma. Rachel Sztajn (2004, p.17) observa que as organizações econômicas visam, de forma eficiente, reduzir os custos de produção mediante a utilização de mecanismos que gerem o máximo de benefícios líquidos e, para Ronald Coase, as firmas são uma forma de desenvolvimento de atividades econômicas, superior aos mercados.

As empresas são consideradas instituições sociais, pois são organizações mediante as quais são ordenadas, providas e estruturadas para ligar os fatores de produção, bem como facilitar a coordenação das suas atividades para os mercados.

Para Rachel Sztajn (2004, p.68), as instituições "são caracterizadas pelo liame que estabelecem entre os indivíduos que as organizam, pela estrutura que as conforma, pelas regras que as definem e que elas aceitam." Pela Teoria da Firma, a empresa é vista com uma unidade técnica de produção, em que se utilizam dos fatores de produção para a geração de bens e serviços. Segundo essa teoria, as firmas trabalham diretamente com a oferta de mercado e são de extrema importância, tendo em vista que reúnem o capital e o trabalho para realizar a produção e são as responsáveis por agregar ao valor as matérias-primas utilizadas nesse processo, por meio da tecnologia.

Outro ponto de destaque é a flexibilidade que deve existir entre as modernas relações empresariais, principalmente no cumprimento dos contratos, devendo esta atividade ser assim desempenhada:

'Flexibilidade' é a chave nos contratos empresariais que, aliás, precisam ser flexíveis para permitir adaptação das regras previstas pelos contratantes no início do negócio às cambiantes condições econômicas, de suprimento, demanda, concorrência, que se apresentam durante o período de execução do contrato, ou mesmo naquele interregno entre a celebração e a execução, quando diferida, evitando-se que as operações sofram e que parecia ser interessante e vantajoso se transforme em pesadelo. (SZTAJN, 2004, p.18).

Deve-se ainda mencionar quando da análise da moderna atividade empresarial a questão da responsabilidade social e ambiental das empresas, destacando-se o seu aspecto socialmente útil de modo a apontar a funcionalidade do conceito.

Amartya Sen menciona a ética empresarial (2000, p.137), ao asseverar que "a economia do bem-estar pode ser substancialmente enriquecida atentando-se mais para a ética, e que o estudo da ética também pode beneficiar-se de um contato mais estreito com a economia." (SEN, 1999, p.105). Faz uma análise sobre o papel dos mercados no desenvolvimento do meio social, considerando que as pessoas podem interagir e dedicar-se a atividades mutuamente vantajosas, enaltecendo a complementaridade. Discorrendo sobre esse aspecto no contexto dos países em desenvolvimento, categoria em que se insere o Brasil, afirma que: 
A necessidade de iniciativa da política pública na criação de oportunidades sociais tem importância crucial. Como já discutido, no passado dos atuais países ricos encontramos uma história notável de ação pública por educação, serviços de saúde, reformas agrárias, etc. O amplo compartilhamento dessas oportunidades sociais possibilitou que o grosso da população participasse diretamente do processo de expansão econômica. (SEN, 2000, p.170).

A população possui um papel fundamental no fortalecimento da responsabilidade social das empresas (OLIVEIRA, 2008), uma vez que seleciona, no ato do consumo, aqueles produtos ou serviços que foram postos à disposição de forma responsável. Segundo Andrew Savitz, a empresa sustentável é aquela que:

[....] conduz seus negócios, de modo a gerar naturalmente um flux de benefícios para todos os seus stakeholders, inclusive para empregados, para empregados, para os clientes, para os parceiros de negócios, para as comunidades em que opera e, obviamente, para os acionistas. (SAVITZ, 2007, p.28).

Muhammad Yunus (2008, p.31) fala em responsabilidade social corporativa, ao mencionar as empresas que exercem suas atividades de maneira sustentável, v.g. evitando a venda de bens defeituosos, sem lançar resíduos tóxicos no meio ambiente.

Atenta ainda para que os lucros de uma empresa responsável permaneçam nela mesmo e que essa atuação é uma forma de mudar o panorama empresarial (YUNUS, 2008, p.37), enaltecendo a importância da lucratividade para o seu desempenho normal. Para isso, esclarece que:

Primeiro, a empresa social criada é auto-sustentável. Não há necessidade de se injetar capital adicional nela todos os anos. É uma empresa que caminha, mantém-se e desenvolve-se por si só. Uma vez estabelecida, ela cresce por conta própria. E assim o investidor obtém mais benefícios sociais para seu dinheiro. Segundo, os investidores de uma empresa social recebem seu dinheiro de volta. Depois disso, eles podem reinvestir na empresa original ou em uma empresa social diferente. Assim, o mesmo dinheiro pode trazer mais benefícios sociais. (YUNUS, 2008, p.39).

Robert Reich (2008,p.174) faz uma leitura crítica da idéia de responsabilidade social das empresas, na medida em que a identifica com problemas relacionados à democracia, comprando referida atuação com um "algodão-doce". A transição para o Supercapitalismo se deu a partir do momento em que as grandes empresas se tornaram mais competitivas, globais e inovadoras, passando a interferir nas decisões políticas. Confira-se o referido posicionamento:

A onda de interesse pela 'responsabilidade social das empresas' se relaciona com a diminuição da confiança na democracia. Hoje em dia os reformadores não raro 
afirmam que é mais fácil convencer executivos de empresas do que políticos; também argumentam que podem ser mais eficazes levando grandes empresas a mudar seu estilo tentando alterar políticas públicas. (REICH, 2008, p.174).

As mudanças de paradigmas nas empresas brasileiras são objetos de pesquisas realizadas pela FIESP, demonstrando que há um crescente esforço das empresas na abertura para a coletividade. Porém, conforme tais dados, as empresas ainda não levam em conta em suas estratégias a responsabilidade social, o balanço social ainda não parece estar organicamente inserido em um processo de planejamento estratégico e de desenvolvimento progressivo das práticas de responsabilidade social empresarial.

\section{O COMPORTAMENTO DO CONSUMIDOR}

Parte-se do pressuposto de que o consumidor elenca suas preferência e conseqüentemente, suas escolhas através do medidor "função utilidade", apreendendo-se o seu nível de satisfação. A restrição orçamentária também está presente nessa análise, haja vista que cada consumidor dispõe de determinado montante para alocar na compra de uma "cesta de consumo". Sobre o assunto, veja-se o que afirma Fábio Ulhôa Coelho:

Nas relações de consumo, a interpretação jurisprudencial das normas jurídicoconsumeiristas pode identificar uma margem maior de atuação da autonomia privada, mas permanecerão vigentes normas de coibição a práticas comerciais abusivas, e assim por diante. O ramo jurídico mais sensível a esse processo de mudanças será, claro, o da disciplina das atividades econômicas. Dependendo das nuanças das relações sociais, talvez se inverta a tendência antiprivativista que marcou o pensamento jurídico ao longo do século, e o direito comercial deixe de ser cada vez mais direito econômico. (COELHO, 2006, p.07).

O Código de Defesa do Consumidor (lei 8.078/90) define no seu art. $2^{\circ}$ que o consumidor é toda pessoa física ou jurídica que adquire ou utiliza produto ou serviço como destinatário final, equiparando-se a coletividade de pessoas, ainda que indetermináveis, que haja intervindo nas relações de consumo. No art. $3^{\circ}$, versa que o fornecedor é toda pessoa física ou jurídica, pública ou privada, nacional ou estrangeira, bem como os entes despersonalizados, que desenvolvem atividade de produção, montagem, criação, construção, transformação, importação, exportação, distribuição ou comercialização de produtos ou prestação de serviços.

O consumidor contemporâneo é bem-informado, consciente, exigente e está acostumado a solicitar alta qualidade nos serviços que lhe são prestados e produtos oferecidos. Sobre os reflexos do comportamento do consumidor na determinação de atividades de uma empresa, registra-se que: 
Esse tipo de comportamento é fruto da mescla de valores sociais aos individuais, acabando por conformá-los, de sorte que as manifestações das partes que levam ao processo decisório refletem muito das instituições e normas sociais que o grupo preza. Preocupadas com a avaliação social das pessoas com quem convive, nem sempre as decisões individuais vão no sentido de maximizar o resultado econômico próprio, o lucro, mas visam muitas vezes, a maximizar ou a não diminuir a estima que os membros da comunidade conferem ou estendem aquele agente. (SZTAJN, 2004, p.15).

Paulo Sandroni (2008, p. 182) menciona a "soberania do consumidor", ao afirmar que esta é a peça-chave do mercado, ou seja, identifica o consumidor como um elemento orientador da produção, quantidade. Registra que essa soberania existiria relacionada à concorrência . Fábio Ulhôa Coelho 2006, p.11), raciocinando nesta mesma linha, considera que os principais atores que se relacionam com a atividade empresarial não se encontram no mercado em igualdade de condições, e, assim, a ordem jurídica, reinterpretando o princípio da isonomia, tem criado mecanismos de desigualdade formal entre os agentes econômicos, de modo a atenuar as diferenças sociais.

\section{A TeOria dOS CUSTOS DE TRANSAÇÃo}

A teoria Neoclássica estuda a empresa pela tecnologia que utiliza para transformar o trabalho, o capital e os insumos em bens e serviços. A principal função do mercado, neste contexto, é fixar preços, sendo este o principal elemento utilizado pelos agentes econômicos para tomar suas decisões sobre consumo e produção. Por seu turno, a teoria Neo-institucionalista define as empresas pelas transações que são realizadas no seu interior, sendo o medidor dos feixes de contratos movimentados em determinada atividade o custo relativo de transacionar hierarquicamente, dentro de uma empresa ou por intermédio do mercado.

O mercado, nesta oportunidade, deve ser entendido como uma instituição que facilita as trocas entre os agentes econômicos, reduzindo os custos de busca, informação, negociação, garantia do cumprimento dos contratos. Para Ronald Coase (1988, p.08), para se realizar uma transação mercadológica faz-se necessário descobrir com quem se quer relacionar, informar aos entes com sobre os termos segundo os quais se deseja negociar, redigir um contrato, cujo conteúdo reflete essa vontade e monitorar o seu cumprimento.

Mas o que são custos de transação? Paulo Sandroni apresenta a seguinte definição:

Conceito relacionado com os custos necessários para a realização de contratos de compra e venda de fatores num mercado composto por agentes formalmente independentes. Esses custos são comparados com aqueles necessários à internalização dessas atividades no âmbito da própria empresa e constituem um 
critério importante na tomada de decisão nas empresas modernas. $\mathrm{O}$ conceito tem relevância também nas teorias desenvolvidas por Ronald Coase que, mediante suas formulações, denominadas Teorema de Coase, estabeleceu que as externalidades (economias externas) não determinam uma alocação imperfeita de recursos desde que os custos de transação sejam nulos. (SANDRONI, 2008, p.218).

Embora seja um conceito que comporta as mais variadas visões, pode-se afirmar que os custos de transação são as atividades e custos necessários para a concretização de uma negociação, a saber: a busca pela informação por partes dos agentes econômicos das circunstâncias em que operam; a atividade de negociação, as quais determinarão as verdadeiras intenções dos compradores e vendedores; a realização e a formalização dos contratos de acordo com o Direito vigente, bem como o monitoramento do cumprimento e, por fim, a correta aplicação desses contratos, de forma a garantir a cobrança de indenização por prejuízos às partes que não seguirem as obrigações pactuadas. (PINHEIRO, SADDI, 2006, p.62). Sobre o assunto, Rachel Sztajn considera que:

As relações são socioeconômicas, devendo-se reconhecer não só a presença da economia, como também o espaço por ela ocupado no desenvolvimento de novas relações, de estruturas sociais, de negócios predispostos para atender às novas exigências das pessoas. (SZTAJN, 2004, p.11).

A teoria dos custos de transação (TCT) trabalha com o conceito de racionalidade limitada ou imperfeita, segundo a qual as pessoas tentam maximizar as suas utilidades, pontuadas pelos limites impostos e pela capacidade de absorver e processar informações. Sobre essa aplicação, Jairo Saddi e Armando Castelar Pinheiro asseveram que:

$\mathrm{Na}$ TCT, o comportamento humano é marcado pelo oportunismo, definido como uma maneira mais forte de buscar o interesse próprio, que pode passar por práticas desonestas, incluindo mentir, trapacear e roubar. Em especial, o oportunismo pode levar as pessoas a esconder ou distorcer informações, para enganar os outros em beneficio próprio. Um agente econômico oportunista só respeita as regras do jogo se isso lhe convier. (PINHEIRO, SADDI, 2006, p.65).

Assim, a principal meta da Teoria dos Custos de Transação é entender como as leis e o Poder Judiciário vão ser balizadores para uma melhor alocação dos recursos, pois a capacidade de economizar os custos de transação dentro de uma determinada empresa é decisiva para aferir quais operações serão feitas dentro desta ou fora, via mercado. 


\section{F. A CONCORRENCIA E A DEFESA DO CONSUMIDOR NAS MODERNAS RELAÇÕES EMPRESARIAIS}

O maior interesse do empresariado é maximizar o lucro com uma alocação de recursos eficiente. Para o consumidor é busca do menor preço possível. Nesse sentido, "a competição reflete a disputa entre as empresas pela possibilidade de vender seus produtos para o maior numero possível de clientes." (PINHEIRO, SADDI, 2006, p.355). Partindo dessa constatação, as manifestações de mercado podem ser agrupadas em três categorias principais: concorrência, monopólio e oligopólio.

Em primeiro lugar, tem-se que a concorrência é a disputa entre produtores de um mesmo bem ou serviço com vistas a angariar a maior parcela do mercado possível, a disputa que se pauta pelo preço, pela qualidade do produto, pela disponibilidade nos pontos de venda e a imagem de que o produto goza junto aos consumidores; as atividades relacionadas à imagem do produto; a publicidade; a programação visual, etc.

O pressuposto para a configuração da concorrência é a existência de grande número de produtores atuando livremente no mercado de um mesmo bem ou serviço, de modo que tanto a oferta quanto a procura se originem em condições de razoável eqüidade, sem influência ilegítima principalmente sobre o preço do produto. Esta é a concorrência positiva, quando se processa dentro do respeito às regras jurídicas e aos direitos do consumidor, promovendo a qualidade do produto e às vezes influi na baixa dos preços. Além disso, não se deve olvidar o aperfeiçoamento tecnológico e a produtividade, que são incrementados pela concorrência.

A concorrência pode ser: perfeita ou pura, imperfeita ou impura, predatória e monopolista.

A concorrência perfeita, que não existe na prática, é aquela pautada pela enorme quantidade de vendedores, todos em uma mesma condição econômica, a informação para o consumidor é a máxima possível, quanto a preços, condições de pagamento; impossibilidade de qualquer vendedor dominar os mercados. A concorrência imperfeita é aquela que se caracteriza pela possibilidade de os vendedores influenciarem na demanda e nos preços, sendo a situação intermediária entre a concorrência perfeita e o monopólio absoluto. A concorrência predatória é situação na qual as empresas entram em um tipo de concorrência cujo resultado são perdas para o conjunto de concorrentes, é uma realidade que não tem vida longa, culminando com acordos de não-agressão ou pela falência das empresas mais fracas. A concorrência monopolista se materializa quando duas ou mais empresas com produtos semelhantes, mas que não necessariamente são substitutos uns dos outros, controlam os preços ao congregar elementos tanto da concorrência perfeita quanto do monopólio.

Por sua vez, o monopólio representa, em poucas palavras, a ausência de concorrência e a existência de um único fornecedor, oportunidade em que o este 
pode impor qualquer preço a suas mercadorias prevalecendo o que lhe dá maior lucro, tendo em vista a relação entre custo e produção, já que é exclusivo. Paulo Sandroni (2008, p.574) assim define os monopólios: "forma de organização de mercado, nas economias capitalistas, em que uma empresa domina a oferta de determinado produto ou serviço que não tem substituto".

Já os oligopólios combinam as características do monopólio e da concorrência, onde há poucos fornecedores e cada um detém uma parcela grande do mercado, de forma que qualquer mudança em sua política de vendas afeta a participação de seus concorrentes e os induz a reagir. Paulo Sandroni (2008, p.574) identifica essa realidade com a concorrência imperfeita. É comum a elaboração de um "acordo de cavalheiros", mais conhecido como cartel, de forma que fixam os mesmos preços como se fosse um monopólio, a exemplo do que ocorre com os postos de combustíveis:

Um cartel, simplificadamente, é um acordo entre empresas participantes de um mesmo mercado para agir conjuntamente com o objetivo de reduzir a concorrência. Quando as empresas formam um cartel, aumentam seu poder de mercado via preço ou via lucro, diminuindo, por outro lado, a eficiência alocativa e o excedente do consumidor. Um cartel é semelhante a uma fusão, mas sem a integração das atividades produtivas, de distribuição ou de marketing das empresas. (PINHEIRO, SADDI, 2008, p.360).

Para Túlio Ascarelli (1952, p.223), "a concorrência obriga os produtores a procurarem, constantemente, a melhoria de seus produtos e a diminuição do seu preço de custo". O principal objetivo da defesa da concorrência é a busca do bem-estar social, "expressão que dá idéia de comodidade, tranqüilidade, sossego e segurança publica" (SILVA, 2008, p.202), além de promover benefícios ou utilidades que serão direcionados para o uso e gozo de uma coletividade, sempre respeitando as regras balizadoras do comportamento empresarial.

A Lei no 8.884/94 regulamenta a defesa da concorrência e estabelece no seu art. 54 a chamada "regra da razão", segundo a qual a operação é aprovada se o beneficio liquido para a sociedade for positivo e reprovada em caso contrário. Confira-se o texto legal:

Art. 54. Os atos, sob qualquer forma manifestados, que possam limitar ou de qualquer forma prejudicar a livre concorrência, ou resultar na dominação de mercados relevantes de bens ou serviços, deverão ser submetidos à apreciação do CADE.

$\S 1^{\circ} \mathrm{O}$ CADE poderá autorizar os atos a que se refere o caput, desde que atendam as seguintes condições:

I - tenham por objetivo, cumulada ou alternativamente:

a) aumentar a produtividade;

b) melhorar a qualidade de bens ou serviço; ou 
c) propiciar a eficiência e o desenvolvimento tecnológico ou econômico;

II - os benefícios decorrentes sejam distribuídos eqüitativamente entre os seus participantes, de um lado, e os consumidores ou usuários finais, de outro; III - não impliquem eliminação da concorrência de parte substancial de mercado relevante de bens e serviços;

IV - sejam observados os limites estritamente necessários para atingir os objetivos visados.

$\S 2^{\circ}$ Também poderão ser considerados legítimos os atos previstos neste artigo, desde que atendidas pelo menos três das condições previstas nos incisos do parágrafo anterior, quando necessários por motivo preponderantes da economia nacional e do bem comum, e desde que não impliquem prejuízo ao consumidor ou usuário final.

$\S 3$ o Incluem-se nos atos de que trata o caput aqueles que visem a qualquer forma de concentração econômica, seja através de fusão ou incorporação de empresas, constituição de sociedade para exercer o controle de empresas ou qualquer forma de agrupamento societário, que implique participação de empresa ou grupo de empresas resultante em vinte por cento de um mercado relevante, ou em que qualquer dos participantes tenha registrado faturamento bruto anual no último balanço equivalente a $\mathrm{R} \$ 400.000 .000,00$ (quatrocentos milhões de reais).

$\S 4^{\circ}$ Os atos de que trata o caput deverão ser apresentados para exame, previamente ou no prazo máximo de quinze dias úteis de sua realização, mediante encaminhamento da respectiva documentação em três vias à SDE, que imediatamente enviará uma via ao CADE e outra à SEAE.

$\S 5^{\circ} \mathrm{A}$ inobservância dos prazos de apresentação previstos no parágrafo anterior será punida com multa pecuniária, de valor não inferior a 60.000 (sessenta mil) Ufir nem superior a 6.000.000 (seis milhões) de Ufir a ser aplicada pelo CADE, sem prejuízo da abertura de processo administrativo, nos termos do art. 32.

$\S 6^{\circ}$ Após receber o parecer técnico da SEAE, que será emitido em até trinta dias, a SDE manifestar-se-á em igual prazo, e em seguida encaminhará o processo devidamente instruído ao Plenário do CADE, que deliberará no prazo de sessenta dias.

$\S 7^{\circ} \mathrm{A}$ eficácia dos atos de que trata este artigo condiciona-se à sua aprovação, caso em que retroagirá à data de sua realização; não tendo sido apreciados pelo CADE no prazo estabelecido no parágrafo anterior, serão automaticamente considerados aprovados.

$\S 8^{\circ}$ Os prazos estabelecidos nos $\S \S 6^{\circ}$ e $7^{\circ}$ ficarão suspensos enquanto não forem apresentados esclarecimentos e documentos imprescindíveis à análise do processo, solicitados pelo CADE, SDE ou SPE.

$\S 9^{\circ} \mathrm{Se}$ os atos especificados neste artigo não forem realizados sob condição suspensiva ou deles já tiverem decorrido efeitos perante terceiros, inclusive de natureza fiscal, o Plenário do CADE, se concluir pela sua não aprovação, determinará as providências cabíveis no sentido de que sejam desconstituídos, total ou parcialmente, seja através de distrato, cisão de sociedade, venda de ativos, cessação parcial de atividades ou qualquer outro ato ou providência que elimine os efeitos nocivos à ordem econômica, independentemente da responsabilidade civil por perdas e danos eventualmente causados a terceiros. $\S 10$. As mudanças de controle acionário de companhias abertas e os registros de 
fusão, sem prejuízo da obrigação das partes envolvidas, devem ser comunicados à SDE, pela Comissão de Valores Mobiliários (CVM) e pelo Departamento Nacional de Registro Comercial do Ministério da Indústria, Comércio e Turismo (DNRC/MICT), respectivamente, no prazo de cinco dias úteis para, se for o caso, serem examinados.

Como se vê, existe regulamentação legal que tem a função de coibir práticas mercadológicas que prejudiquem a livre concorrência, sendo a atuação do CADE significativa nesse ponto. As forças do mercado, por vezes, "esquecem" a letra da lei, mas a defesa de uma ordem econômica legítima é o principal alvo.

\section{Conclusão}

A Análise Econômica do Direito moldou com suas ferramentas a moderna atividade empresarial, coadunando-a com a proteção do consumidor e a defesa da concorrência, com a finalidade precípua de inserir a atuação do empresariado em um contexto normatizado.

Resta, desta feita, constatado que os postulados da AED são utilizados decisivamente em diversos ramos do Direito e que a moderna atividade das empresas é fortemente influenciada pelo jogo da Economia, na medida em que as diretrizes para a aplicação, formulação e interpretação das normas jurídicas têm por função precípua aumentar o grau de segurança, previsibilidade e eficiência das relações jurídicas.

Assim, as relações entre o Direito e a Economia são cada vez mais estreitas, de modo que a influência é dinâmica e recíproca. As forças do mercado são constantemente balizadas pelas normas jurídicas, que têm como principal papel normatizar e orientar as modernas práticas empresárias, focando principalmente em uma eficiente alocação dos recursos e na proteção do consumidor. Trata-se, portanto, de uma atuação mais funcional e orientada.

\section{REFERÊNCIAS}

AGUILLAR, Fernando Herren. Direito Econômico: do Direito nacional ao direito supranacional. São Paulo: Atlas, 2006.

ASCARELLI, Túlio. Os contratos de cartel e os limites de sua legitimidade no direito brasileiro. Ensaios e pareceres. São Paulo: Saraiva, 1952.

COASE, Ronald. The firm, the market and the Law. Chicago: University press, 1988.

COELHO, Fábio Ulhôa. Curso de Direito Comercial. 10. ed. rev. atual. v. I, São Paulo: Saraiva, 2006. 
FORGIONI, Paula A. Análise econômica do direito (AED): Paranóia ou mistificação? Revista de direito mercantil, industrial, econômico e financeiro. São Paulo: Malheiros, Ano XLIV, julho-setembro/2005, p. 244-247.

GALGANO, Francesco. Lex mercatoria. Bolonha: Il mulino, 1976.

OLIVEIRA, José Antônio Puppim de. Empresas na sociedade. Rio de Janeiro: Elsevier, 2008.

POSNER, Richard. Economic analysis of law. 5. ed. Nova Iorque: Aspen, 1998.

REICH, Robert. Supercapitalismo: como o capitalismo tem transformado os negócios, a democracia e o cotidiano. Rio de Janeiro: Elsevier, 2008.

SADDI, Jairo. PINHEIRO, Armando Castelar. Direito, Economia e Mercados. Rio de Janeiro: Elsevier, 2006.

SANDRONI, Paulo. Dicionário de Economia do século XXI. 4. ed. Rio de Janeiro: Record, 2008.

SAVITZ, Andrew W. A empresa sustentável. 2. ed. Rio de Janeiro: Elsevier, 2007.

SEN, Amartya Kumar. Sobre ética e economia. Trad. Laura Teixeira Motta. 7. ed. São Paulo: Companhia das Letras, 1999.

. Desenvolvimento como liberdade. Trad. Laura Teixeira Motta. 7. ed. São Paulo: Companhia das Letras, 2000.

SILVA, De Plácido. Vocabulário jurídico. 27. ed. Rio de Janeiro: Forense, 2008. SZTAJN, Rachel. Teoria Jurídica da Empresa: atividade empresária e mercados. São Paulo: Atlas, 2004.

.Função social do contrato e direito de empresa. Revista de direito mercantil:

industrial, econômico e financeiro, v. 44, n. 139, jul./set., 2005, p. 29-49

. ZYBERSZTAJN, Decio. Direito e economia: Análise Econômica do Direito e das Organizações. Rio de Janeiro: Elsevier, 2005.

YUNUS, Muhammad. Um mundo sem pobreza: a empresa social e o futuro do capitalismo. São Paulo: Ática, 2008. 


\section{THE ECONOMIC ANALYSIS OF LAW AND MODERN BUSINESS ACTIVITY}

Abstract: This article aims to analyse the behavior of firms facing the consumer market, as dictated by the Economic Analysis of Law (AED). There will be some considerations about the AED, through the study of modern business activity, from the viewpoint of the theory of transaction costs, the consumer market. Finally, is shows that there is a significant relationship between the Law and Business and economic order marked as the role of business today.

Keywords: Economic Analysis of Law. Companies. Consumer. 